\begin{tabular}{l|l|}
$\begin{array}{l}\text { D. Esterhuizen } \\
\text { C.S.L. Schutte }\end{array}$ & Enhancing innovation capability maturity through \\
A.S.A du Toit & knowledge sharing
\end{tabular}

\title{
ENHANCING INNOVATION CAPABILITY MATURITY THROUGH KNOWLEDGE CONVERSION
}

\section{Esterhuizen: Department of Industrial Engineering, University of Stellenbosch C.S.L. Schutte: Department of Industrial Engineering, University of Stellenbosch A.S.A du Toit: Centre for Information and Knowledge Management, University of Johannesburg}

Purpose: This research was aimed at investigating organisational support by means of knowledge conversion processes toward
maturity growth in innovation capability areas.
Problem investigated: No formal guidelines exist for the use of knowledge management to grow innovation capability maturity.
As knowledge management plays a fundamental role in an enterprise's ability to innovate successfully, the following question
arises: Can knowledge creation processes be used to enable innovation capability maturity growth?
Methodology: The literature therefore provides a strong basis for the argument that knowledge management and more
specifically knowledge creation processes could be used to improve an enterprise's innovation capability maturity. A knowledge
creation framework that enables innovation capability maturity growth was designed by aligning knowledge creation processes to
the requirements for innovation capability growth from one maturity level to the next. The time-frame of the research did not allow
the implementation of the framework, and five industry and subject theory experts were used to evaluate the framework.
Findings: All five experts responded positively to, and were in agreement that the reasoning applied when identifying the specific
knowledge creation process path as a key enabler of growth between innovation capability maturity levels is logical and sound.
Value of research: The unique research contribution of the framework lies in providing a tangible link between the fields of
knowledge management and innovation capability maturity.
Conclusion: The impact of this research lies in the development of a knowledge creation framework that provides guidelines for
the use of knowledge creation processes as a vehicle for innovation capability maturity growth.
Keywords: Innovation Capability Maturity, Knowledge Management, Knowledge Sharing Processes

\section{INTRODUCTION}

The competitiveness and survival of the modern enterprise are reliant on its ability to innovate, providing a strong argument that innovation should not be apportioned to only the final levels of organisational maturity. The notion of innovation goes as far back as 1934 in the works of Schumpeter. In 1939, Schumpeter (1939:48) directly addressed the vague concept of innovation, defining it as encompassing the entire process, starting from a kernel of an idea, continuing through all the steps to reach a marketable product that changes the economy. He also singled out five types of innovation: those that result in new products, new methods of production, new sources of supply, the exploration of new markets, and new ways to organise business. Bigoness and Perreault (1981:68) argue that the adoption of a single process, product or business concept by an enterprise does not necessarily represent a tendency toward innovativeness. They suggest that it is the enterprise that consistently adopts innovative ideas that appropriately demonstrates innovative characteristics.

Furthermore, it is vital that the innovation process continues in order to maintain and improve on any competitive advantage derived from previous initiatives through new and promising opportunities. This notion is affirmed by Moore (2005:84) when he compares enterprises and markets to nature, which demands persistent evolution to maintain equilibrium and sporadic revolution to create advantage. As 


\begin{tabular}{l|l} 
D. Esterhuizen & Enhancing innovation capability maturity through \\
C.S.L. Schutte & knowledge sharing
\end{tabular}

innovation is the source of this evolution and revolution, it is not only a current issue, but also a permanent one.

Knowledge management plays a pivotal role in an enterprise's ability to innovate successfully, which leads to the pertinent question of how knowledge conversion can be used to enhance innovation in companies. The existing literature on the subject is sparse, at most implying a relation between knowledge management and an enterprise's innovation capability. Innovation is widely considered a key prerequisite for achieving organisational competitiveness and sustained long-term wealth in our increasingly volatile business environment. It is therefore imperative that enterprises enable themselves to relentlessly pursue constant innovation; to grow and mature their innovation capability. Therefore, this research was aimed at investigating organisational support by means of knowledge conversion processes toward maturity growth in innovation capability areas.

A literature review of the innovation landscape led the authors to identify the need for enterprises to grow and mature their innovation capability. Further reading highlighted the direct connection between innovation and knowledge management; knowledge creation processes act as critical enablers for the innovation process. From this the following research problem statement was developed: No formal guidelines exist for the use of knowledge management to grow innovation capability maturity. As knowledge management plays a fundamental role in an enterprise's ability to innovate successfully, the following question arises: Can knowledge creation processes be used to enable innovation capability maturity growth?

\section{INNOVATION}

Innovation is a key prerequisite for achieving organisational competitiveness and long-term wealth in the volatile business environment. Being able to innovate, and do so on a constant and sustainable basis, is widely considered vital for enterprises functioning within the competitive realm (Cavusgil, Calantone \& Zhao, 2003:9).

The literature indicates various seemingly different types of innovation; notably innovation regarding products, services, processes, strategy, marketing, finance and value. Still, these regularly overlap in definition. The most common categorisation for innovation is into two high-level categories, namely product and process innovation (Katz, 2007:15). Neely, Filippini, Forza, Vinelli and Hii (2001:116) explain that product innovation involves the development and commercialisation of new tangible products or services, while process innovation involves the introduction of new, or the improvement of current manufacturing, distribution and service processes; any procedure or action that is implemented to execute the transformation of resources associated with the enterprise. Du Preez, Schutte, Essmann, Louw and Marais (2009:20) further emphasise that, with product innovation, both parties involved (the enterprise and the customer) should gain value from the transaction. They also argue that process innovation can relate to a high-level managerial process, or to a detailed set of tasks to execute an operational process.

In addition to product and process innovation categories, Baker (2002) highlights the importance of a third type of innovation: strategy innovation. He argues that product and process innovation alone are no longer adequate, necessitating the introduction of strategy innovation to provide further support. This type of innovation emphasises the importance of a long-term view of the contribution of innovation toward the competitiveness and success as an enterprise. Hamel (2000:48) confirms this, referring to strategy innovation as business concept innovation $(\mathrm{BCl})$. $\mathrm{BCl}$ involves innovations to a variety of business design variables, including pricing structures, distribution channels and value webs or relationships. 


\section{Esterhuizen \\ C.S.L. Schutte \\ A.S.A du Toit}

\section{Enhancing innovation knowledge sharing}

\section{capability maturity through}

With innovation being categorised into product, process and strategic innovation, it is necessary to add that a successful innovation is often a combination of the three types of innovation, as a new strategy can result in a new product, which in turn requires a new process (Du Preez et al., 2009:42). However, enterprises often confuse invention for innovation. Tidd and Bessant (2009:68) agree, stating that "innovation is more than simply coming up with good ideas: it is the process of growing them into practical use". They argue that the innovation process primarily consists of four core actions: search, select, implement and capture. In short, the two fundamental aspects characterising any type of innovation are therefore a novelty or newness associated with innovation activities; and the presence of an inherent process.

As innovation necessitates the execution of a process, this process may be represented as a life cycle of phases. Du Preez et al. (2009:35) describe a basic and generic representation of the innovation lifecycle that comprises the following phases:

- Invention: Opportunities are identified and ideas generated, with creativity playing an important role.

- Feasibility: The feasibility of these ideas are determined through rigorous testing and screening. The specification, functional analysis and initial design are also executed.

- Implementation: The feasible ideas and opportunities from the previous phase are now further designed and implemented in the enterprise, or offered to the market.

- Operation: Once the process has delivered a commercially viable output, operation is undertaken. This encompasses the performance of activities such as production and quality control of products, monitoring and optimisation of processes, and deployment of strategy.

- Disposal: After maximum feasible utilisation has been attained, the innovation process enters into its final phase, that of disposal. Here, the focus is on reflecting and learning from the process and fulfilling final (legal, environmental, etc.) obligations. Disposal does not refer to the conclusion of the innovation process, but rather to the closure of the particular initiative.

Essmann (2009:54) points out that learning occur in the activities through all innovation lifecycle phases. At the end of each phase, there is an opportunity to learn from the successes and failures of that phase. The innovation lifecycle phases may be revisited in order to re-execute certain activities or to refine certain aspects and improve upon the initiative.

Furthermore, it is vital that the innovation process continues in order to maintain and improve on any competitive advantage derived from previous initiatives through new and promising opportunities. This notion is affirmed by Moore (2005:103) when he compares enterprises and markets to nature, which demands persistent evolution to maintain equilibrium and sporadic revolution to create advantage. As innovation is the source of this evolution and revolution, it is not only a current issue, but also a permanent one. Moore (2005:105) is widely quoted for stating: "To innovate forever, in other words, is not an aspiration; it is a design specification. It is not a strategy; it is a requirement".

\section{INNOVATION CAPABILITY MATURITY AND CAPABILITY MATURITY MODELS}

It is a common misconception that innovation must be completely novel. Essmann (2009:14) highlights that this is far from the truth. He argues that common processes and previously acquired knowledge and competencies, supported by the appropriate organisational structures, strategy, climate, culture and leaders, can collectively contribute to an environment that enables and/or is favourable for innovation. With innovation capability being the organisational means with which innovative outputs may be generated, Essmann (2009:23) points out that this innovation capability must be assessed and improved to sustain, repeat and accelerate innovative initiatives. This requirement for assessment and constant improvement directly translates to the concept of capability maturity models. 


\section{Esterhuizen \\ C.S.L. Schutte \\ A.S.A du Toit}

\section{Enhancing innovation capability maturity through knowledge sharing}

Generically, a capability maturity model can be seen as a method for judging whether processes used, as well as the way in which they are used, are characteristic of a mature enterprise (Fairchild, 2004:141). It is a set of structured levels that defines how well the activities, practices and processes of an enterprise can reliably and sustainably produce the required outcomes.

The two essential goals of a capability maturity model are to determine the capability maturity of an enterprise in terms of a specific domain of practice; and consequently to facilitate in establishing and guiding improvement that will best suit the enterprise and that complies with the prescribed best practices of the domain (Essmann, 2009:18).

The abovementioned provides a platform for logical reasoning regarding the importance of capability maturity models. In order to understand the current positioning of an enterprise relevant to its competitors as well as enterprises in other industries, it is necessary to establish its capability maturity in terms of a specific domain of practice. Moreover, it is important for an enterprise to benchmark itself against the best or against those who are known to be successful, in order to determine how much and in what direction to improve. Although benchmarking is a recognised practice, it can present a problem, as most enterprises are reluctant to expose their competitive secrets. Here Essmann (2009:32) points to a possible solution: Capability maturity models are available from creators who have used many resources to establish best practices for a specific domain, and it is against these best practices that an enterprise should benchmark itself.

The original Capability Maturity Model ${ }^{\circledR}$ for software (SW-CMM®) is a widely accepted set of guidelines for developing high-performance software enterprises (LeVasseur, 2001:51). The original concept behind SW-CMM $\circledast$ was developed in the early 1980 s by Watt Humphrey and colleagues at IBM. He placed the emphasis for improving software development on the process, after establishing that the quality of software was directly related to the quality of the process used to develop it (LeVasseur, 2001:58).

However, the Software Engineering Institute (SEI) of Carnegie Mellon University developed the original SW-CMM® and first published it under the sponsorship of the United States Department of Defence (Cooke-Davies, 2004:112). The majority of capability maturity models are based on the initial SW-CMM® of the SEI (Essmann, 2009:64).

SEI compiled the Capability Maturity Model Integration $\AA$, or $\mathrm{CMMI}$, which is a model consolidated from the following bodies of knowledge (or domains of practice): software development, systems engineering, integrated product and process development, and supplier sourcing. Degen-Hientz, Fäustle and Hörmann (2005:1) describe the CMMI development and maintenance of products and services throughout the product lifecycle.

The concept of the Capability Maturity Model, or simply the maturity model, has since spread to many organisational domains of practice. Champlin (2003:61) affirms this, stating that the enterprise has a wide selection of capability maturity models from which to choose, not only between applications, but also within each application, as capability maturity models have been developed for many applications, including software development, IT management, project management, data management, business management and knowledge management.

Most capability maturity models have the same basic five-level maturity scale structure, with maturity level descriptions often corresponding between the different models. ${ }^{1}$ The CMMI® Product Team (2002:48) defines a maturity level as a "well-defined evolutionary plateau of process improvement".

\footnotetext{
${ }^{1}$ This is possibly due to the fact that the SW-CMM® formed the basis of the majority of other capability maturity models.
} 


\section{Esterhuizen \\ C.S.L. Schutte \\ A.S.A du Toit}

\section{Enhancing innovation capability maturity through knowledge sharing}

An enterprise does not necessarily start at maturity level 1; it is benchmarked against the capability maturity descriptions of each level and is then assigned the appropriate level on the condition that it continues to fulfil the requirements as stated in the description for that level. When assigning a specific level it is also assumed that all the requirements for the previous levels have been met. To have attained maturity level 4, for example, all the requirements of levels 2, 3 and 4 must have been continuously fulfilled and institutionalised. Level 1 serves as the launch pad for successive levels and does not imply that any maturity requirements have been met.

Innovation has been unmistakably linked to constant evolution and revolution (Hamel, 2000:75). The $\mathrm{CMMI}{ }^{\circledR}$ aptly deals with this problem of constant change by stipulating innovation as a requirement. This requirement is however only addressed by enterprises that have attained a level 4 maturity and are now working toward maturity level 5 therefore indicating that innovation is reserved only for enterprises with a high level of capability maturity.

Of the 567 organisations that have undergone a SCAMPI ${ }^{2}$ appraisal conducted from its April 2002 release until December 2004, 69.7\% fell into levels 1, 2 and 3 (Degen-Hientz et al., 2005:6), and therefore were not addressing innovative ways of executing domain-specific activities. Even though this is representative of a single maturity model, it is the successor of the maturity model on which most other maturity models are based - the SW-CMM®.

Innovation across all capability maturity levels is crucial for enterprise survival and therefore represents an essential omission in the original $\mathrm{SW}-\mathrm{CMM}{ }^{\circledR}$, its successor $\mathrm{CMMI}$, and the many maturity models that are based thereon. The competitiveness and survival of the modern enterprise are reliant on its ability to innovate, providing a strong argument that innovation should not be apportioned to only the final levels of organisational maturity.

An initial reaction to this problem could be to suggest the following solution: Skip straight to the highest level of maturity in order to address the innovation imperative. This is, however, an invalid argument, as the CMMI® explicitly states that maturity levels should not be skipped (Shrum \& Phillips, 2004:16). The levels build upon the essential assumption that the requirements of previous levels have been met; disregarding this could lead to the omission of certain basic requirements and result in essential exclusions regarding domain practices.

However, the problem that innovation should not be apportioned to only the final levels of organisational maturity can be addressed by modifying existing capability maturity models so that they require innovation at earlier levels of maturity. Alternatively, a new maturity model specifically aimed at innovation capability is required.

Some recent and/or significant developments regarding innovation capability maturity models include the Innovation Capability Maturity Model from Indutech by Essmann (2009), the Business Innovation Maturity Model from Accelper Consulting (Gupta, 2010), the INPAQT Innovation Capability Maturity Model from INPAQT (2010), the Innovation Maturity Model from Tata Consultancy Services Ltd (Narayana, 2005), the Innovation Maturity Model from OVO (2010), the Innovation Maturity Model from PRTM (2007), the Innovation Maturity Model from Think For A Change (2009) and the Innovation Aptitude ${ }^{\mathrm{TM}}$ Audit from The Innovation Practice (2007).

\footnotetext{
${ }^{2}$ Standard CMMI® Appraisal Method for Process Improvement (SCAMPI), v. 1.1 Class A.
} 


\section{Esterhuizen \\ C.S.L. Schutte \\ A.S.A du Toit}

\section{Enhancing innovation capability maturity through knowledge sharing}

Even though they are applied in practice, insufficient information is available to distinguish between these models and the theoretical and/or empirical foundations of these innovation capability maturity models are unclear; all except for the Innovation Capability Maturity Model (ICMM) by Essmann (2009). ICMM (2009) is a capability maturity model that describes an innovation capability maturity improvement path for competitively orientated enterprises, with the aim of capturing and improving an enterprise's capability to innovate.

The following is a description of the respective generic innovation capability maturity levels (with implicit intermediate levels between 1 and 3 , and 3 and 5), as specified by the ICMM:

- Maturity level 1: Ad hoc and limited: Innovation-related practices and procedures are impromptu and limited in their ability to fulfil the requirements for consistent innovation.

- Maturity level 3: Formalisation and predictability: Innovation-related best practices and procedures have been identified and deployed, enabling the consistent fulfilment of the requirements for innovation. This does not imply the deployment of a rigid and stifling structure that must be conformed to, but rather a proactive and planned approach to innovating.

- Maturity level 5: Integration, synergy and autonomy: Once formalisation has been attained, institutionalisation of practices emerges, in other words where activities become natural behaviour. This enables individual autonomy, and the freeing up of resources to concentrate on achieving alignment and synergy within and between innovation initiatives and with operational activities.

The primary content of the ICMM deals with the core requirements for innovation capability. These 42 innovation capability requirements are structured within the model, each with its own specific level 1, 3 and 5 maturity level scenario descriptions modelled on the generic maturity level descriptions. Although the scope of this article does not necessitate a detailed account of the ICMM, listing a few of the requirements might provide context as to the application of the ICMM:

- Developing and conveying innovation strategy and objectives.

- Championing and encouraging innovation.

- Involving customers and suppliers in the innovation process.

- Planning and coordinating the innovation portfolio.

- Reducing uncertainty and mitigating risk.

- Establishing intellectual property management and sharing policy.

- Capturing, storing and retrieving data and information.

\section{INNOVATION AND KNOWLEDGE MANAGEMENT}

Davenport and Prusak (2000:119) convey what is meant by knowledge within the context of the enterprise and highlight the characteristics that make knowledge valuable, as well as those that make it hard to manage: "Knowledge is a fluid mix of framed experience, values, contextual information, and expert insight that provides a framework for evaluating and incorporating new experiences and information. It originates and is applied in the minds of knowers. In enterprises, it often becomes embedded not only in documents or repositories but also in organisational routines, processes, practices, and norms."

The knowledge economy requires improvisation and constant innovation (Tremblay 2003). Enterprises realise competitive advantage through the use of knowledge and innovation, created and stored in the minds of their knowledge workers (King, Kruger \& Pretorius, 2007; Mercer 2008). Davenport (2005) in describing the knowledge worker in the present day enterprise argues: "Knowledge workers are responsible for sparking innovation and growth in your organization. They invent your new products and services, design your marketing programs, and create your strategies. In the current economy, they are the horses that pull the plow of economic progress. If our companies are going to be more profitable, if our strategies are going to be successful, if our society is going to become more advanced - it will be because 


\section{Esterhuizen \\ C.S.L. Schutte \\ A.S.A du Toit}

\section{Enhancing innovation capability maturity through knowledge sharing}

knowledge workers did their work in a more productive and effective manner". Knowledge and innovation are complementary issues and their impact on the enterprise should not be viewed as two singular and mutually exclusive inputs. According to Murray and Rowan (2000) innovation, which is research-based, is critical in the generation of wealth, increased economic activity and economic diversification. "Researchbased innovation is about expanding our ability to create new wealth". To illustrate the complementary relationship between knowledge management and innovation further, Murray and Rowan (2000) expand on the view of synergy between innovation and knowledge management by stating that knowledge capital is the "primary driver of innovation dynamics that create and maintain superior innovating power", and for an enterprise to maintain this, it must be able to move beyond its existing paradigms and mindsets to meet the demands of competition and the growing needs for multidisciplinary knowledge.

The creative and innovative use of knowledge workers is emphasised by BRINT.com (2004), through the definition of knowledge management as a set of organisational processes that strive to achieve synergy between information systems and the nature of workers to innovate. Motivating and nurturing the professional skills of knowledge workers will enable them to generate and share knowledge. The emphasis is on the conversion of ideas into commercial applications - the starting point being the creation of an idea. According to Ruggles and Little (1997:21), knowledge management activities are adding value to enterprises by enhancing innovation and innovativeness. They propose that management's role should be "to carefully combine activities which enable and encourage ideas to be generated and grow, support their diffusion, and harvest the value for the organization". Darroch (2005:112) emphasises the importance of knowledge management to enhance innovation and performance within enterprises. Her study provides empirical evidence that an enterprise that is knowledge management proficient will be more innovative and will perform better. Effective knowledge management and knowledge creation thus become a precursor to innovation.

Cavusgil, Calantone and Zhao (2003) investigated how firms acquire tacit knowledge from partner firms and how the extent of inter-firm tacit knowledge transfer affects firm innovation capability. Calantone, Cavusgil and Zhao (2002:517) examined the concept of learning orientation and its effect on firm innovation capability. Lin (2007) examined the influence of individual factors (enjoyment in helping others and knowledge self-efficacy), organisational factors (top management support and organisational rewards) and technology factors (ICT use) on knowledge-sharing processes and whether a presence of more of these factors leads to superior organisational innovation capability. The existing literature regarding formalised guidelines for the use of knowledge creation processes to enable innovation capability maturity growth is sparse and this gap in the literature provides the platform for the work presented in this article.

\section{KNOWLEDGE CONVERSION}

Martensson (2000:207) points out that most literature that view knowledge as a process corresponds to a model or theory of knowledge management that comprises individual yet related stages or phases. Knowledge is firstly acquired before it is entered, organised and stored in a system. Stored knowledge is then made accessible and distributed timeously into the hands of the right users, with the goal of utilising and sharing it through socialisation or exchange in digital or analogue form.

Nonaka and Von Krogh (2009:639) define organisational knowledge creation as "the process of making available and amplifying knowledge created by individuals as well as crystallizing and connecting it to an organization's knowledge system", while emphasising that knowledge conversion is a significant result of knowledge management in enterprises. 


\section{Esterhuizen \\ C.S.L. Schutte \\ A.S.A du Toit}

\section{Enhancing innovation capability maturity through knowledge sharing}

More than 15 years ago, Nonaka (1994) presented ground-breaking premises with the development of the SECI model that shaped the development of organisational knowledge creation theory as it exists today. Gourlay (2006:417) points out that the yearly increase in the number of citations, as well as the range of categories of journals in which this publication has been cited, is indicative of a level of interest that deems his research outputs very important work. However, issues have since then been raised regarding these premises, and in 2009 Nonaka and Von Krogh (2009) presented an extensively researched article on the concepts of tacit knowledge and knowledge conversion, discussing controversies and advancements that have since developed in the organisational knowledge creation theory domain.

Nonaka's well-known SECI model relates how an enterprise creates knowledge through the interactions between explicit knowledge and tacit knowledge. Explicit and tacit knowledge grow in both quality and quantity during the process of knowledge conversion. The four modes of knowledge conversion are socialisation, externalisation, combination and internalisation (Nonaka, 1994:25).

- Socialisation: Tacit to tacit knowledge transfer is referred to as socialisation. Since tacit knowledge is difficult to formalise and often time- and space-specific, tacit knowledge is acquired and converted only through shared experience. Socialisation typically occurs when sharing the same environment. Examples include a traditional apprenticeship (apprentices learning the tacit knowledge needed in their craft through hands-on experience, rather than from written manuals or textbooks) and informal social meetings outside of the workplace (creating and sharing world views, mental models and mutual trust). It also occurs beyond organisational boundaries (acquiring and taking advantage of the tacit knowledge embedded in customers or suppliers) (Nonaka, 1994:26).

- Externalisation: Explicit to tacit knowledge transfer is referred to as externalisation. Knowledge is formed when tacit knowledge is articulated into explicit knowledge. This allows it to be shared by others, and it then becomes the basis of new knowledge. Tacit knowledge becomes explicit through metaphors, analogies, concepts, hypotheses or models. An example of externalisation is a qualitycontrol circle that allows employees to make improvements on the manufacturing process by articulating the tacit knowledge of the enterprise accumulated over years on the job (Nonaka, 1994:27).

- Combination: Transferring explicit knowledge to more complex and systematic sets of explicit knowledge is referred to as combination. Explicit knowledge is gathered internally in or external to the enterprise and then combined, edited or processed to form new knowledge, which is then disseminated among the members of the enterprise. This process can be supported through the creative use of computerised communication networks and large-scale databases. Examples of the combination process are collecting and contextualising organisation-wide information to form a financial report, or breaking down a corporate vision into operationalised business or product concepts, where the financial report and operationalised business or product concepts represent new explicit knowledge (Nonaka, 1994:28).

- Internalisation: Explicit to tacit knowledge transfer is referred to as internalisation, which is closely related to 'learning by doing'. Created explicit knowledge is shared throughout an enterprise and converted into tacit knowledge by individuals as they embody it. Explicit knowledge has to be actualised through action and practice; for example, by reading documents or manuals about their jobs and the enterprise and by reacting upon them, trainees can internalise the explicit knowledge written in such documents to enrich their tacit knowledge base. Explicit knowledge can be also embodied through simulations or experiments that trigger learning by doing.

Knowledge becomes a valuable asset when it is internalised and becomes part of an individual's tacit knowledge base in the form of shared mental models or technical know-how. This tacit knowledge can then set off a new spiral of knowledge creation when the individual shares it with others through socialisation. 


\section{Esterhuizen \\ C.S.L. Schutte \\ A.S.A du Toit}

\section{Enhancing innovation capability maturity through knowledge sharing}

Nonaka and Toyama (2003:6) emphasise that the interaction between tacit and explicit knowledge is amplified through the four knowledge creation processes and forms a spiral, not a circle. This spiral becomes larger in scale as it moves up the ontological levels (from individual to group to enterprise to inter-enterprise). Knowledge created through the SECI process can also trigger a new spiral of knowledge creation. The spiral therefore expands horizontally and vertically through communities of interaction that span across all boundaries, as "knowledge created by the organization can trigger the mobilization of knowledge held by outside constituents such as consumers, affiliated companies, universities, or distributors" (Nonaka \& Toyama, 2003:8).

Although the scope of this article does not allow for a reiteration of all critique presented in the past 16 years since the publication of Nonaka's knowledge creation theory, it is reassuring to note that after intense scrutiny, Nonaka and Von Krogh (2009:652) conclude by proposing to maintain the two premises in organisational knowledge creation theory, as "they serve theory building and empirical research on creativity, change, innovation, and learning in organization science".

Nonaka's knowledge creation model (Nonaka, Toyama \& Konno, 2000) relates how enterprises, rather than individuals, create knowledge. The model comprises of three elements that have to interact dynamically to form the knowledge spiral that creates knowledge. A concise summary of these three elements as well as their interaction is presented below. The aim is to provide a pragmatic mental picture without losing the importance and context of interaction between the elements through oversimplification.

- The SECI model: The SECI model uses socialisation, externalisation, combination and internalisation processes of creating knowledge through conversion between tacit and explicit knowledge (described previously in this section).

- "Ba": The shared context needed to create knowledge Ba represents a place where information is interpreted to become knowledge, but it does not necessarily mean a physical space; it can be an office space, a virtual space such as e-mail or a mental space such as shared ideals. Ba is the context shared by those who interact with each other, so that those who interact and participate in ba, as well as the context itself, evolve through self-transcendence to create knowledge. Ba provides the energy, quality and place to perform the individual conversions and to move along the knowledge spiral.

- Knowledge assets: The input, output, and moderating factorsThe role of knowledge assets in the knowledge creation process is best illustrated as follows: While trust among organisational members is created as an output of the knowledge creation process, it also moderates how ba functions as a platform for the knowledge creation process. There are four types of knowledge assets: experiential knowledge assets (shared tacit knowledge built through interaction, e.g. skills, know-how), conceptual knowledge assets (explicit knowledge articulated through images, symbols and language), systemic knowledge assets (systematised explicit knowledge, e.g. technologies, product specifications, manuals) and routine knowledge assets (tacit knowledge that is routinised and embedded in actions and practices of the enterprise, e.g. know-how, organisational culture and organisational routines).

When the innovation capability maturity of an enterprise is evaluated, the enterprise is benchmarked against the requirements of the maturity level description of each innovation capability and is assigned the appropriate level. Consequently, this enterprise has then grown in its innovation capability maturity when it is again benchmarked against the requirements of each maturity level, and it is determined that the innovation-related activities of the enterprise has improved to such an extent that it is now benchmarked against a higher maturity level description.

To grow innovation capability maturity is then, in practice, synonymous with an enterprise improving its innovation-related activities to such an extent that it is now benchmarked against a higher maturity level description. How can knowledge creation processes be used to enable the enterprise to improve its innovation-related activities in such a way as to move from one maturity level description to a higher maturity level description? 


\begin{tabular}{l|l}
$\begin{array}{l}\text { D. Esterhuizen } \\
\text { C.S.L. Schutte }\end{array}$ & $\begin{array}{l}\text { Enhancing innovation capability maturity through } \\
\text { knowledge sharing }\end{array}$ \\
A.S.A du Toit &
\end{tabular}

An answer to this question depends on an understanding of the key knowledge-related needs when moving upwards between maturity levels or, approaching it from a different angle: What are the key knowledge actions (and therefore the key knowledge creation processes) that enable innovation capability growth from one maturity level to the next?

\section{KNOWLEDGE CREATION FRAMEWORK TO GROW INNOVATION CAPABILITY MATURITY}

Knowledge management plays a fundamental role in innovation, leading to the question of whether knowledge creation processes can also be used to grow innovation capability maturity. The literature review in the previous sections confirms that knowledge conversion emerges as a central theme in knowledge management, with knowledge creation processes in turn lying at the core of knowledge creation theory. The literature therefore provides a strong basis for the argument that knowledge management and more specifically knowledge creation processes could be used to improve an enterprise's innovation capability maturity.

Growing innovation capability maturity is, in practice, synonymous with an enterprise improving its innovation-related activities to such an extent that it is now benchmarked against a higher maturity level description. How can knowledge creation processes be used to enable the enterprise to improve its innovation-related activities in such a way as to move from one maturity level description to a higher maturity level description?

An answer to this question depends on an understanding of the key knowledge-related needs when moving upwards between maturity levels. Approaching the question from a different angle: What are the key knowledge actions (and therefore the key knowledge creation processes) that enable innovation capability maturity growth from one level to the next? (Refer to

Figure1.) 


\begin{tabular}{l|l} 
D. Esterhuizen & $\begin{array}{l}\text { Enhancing innovation capability maturity through } \\
\text { knowledge sharing }\end{array}$ \\
A.S.A Schutte &
\end{tabular}

Figure 1: Key knowledge creation processes to enable growth? 
D. Esterhuizen

C.S.L. Schutte

$\begin{gathered}\text { "Which knowledge transfer } \\ \text { processes are key to enable } \\ \text { growth from maturity level }\end{gathered}$
processes are key to enable
growth from maturity level

Growing from maturity level 1 to 3 : Key knowledge creation processes

Considering the ICMM innovation capability maturity descriptions in 


\begin{tabular}{l|l}
$\begin{array}{l}\text { D. Esterhuizen } \\
\text { C.S.L. Schutte }\end{array}$ & $\begin{array}{l}\text { Enhancing innovation capability maturity through } \\
\text { knowledge sharing }\end{array}$ \\
A.S.A du Toit &
\end{tabular}

Figure1, the knowledge creation process that acts as a key enabler for innovation capability maturity growth between maturity level 1 and maturity level 3 was identified through the following reasoning: In order to grow from maturity level 1 to maturity level 3, the enterprise needs to improve its innovationrelated activities from a state where these activities are mostly ad hoc and informal to a state where they have been formalised into best practices and procedures.

What are the key knowledge actions (and therefore the key knowledge creation processes) that are needed to move from a state where activities are ad hoc to a state where activities are formalised?

The key knowledge action that will facilitate this growth is that the enterprise is able to 'define' its innovation-related activities. Here the key knowledge creation process is externalisation; making tacit knowledge regarding innovation-related activities that reside in the heads of workers tangible (explicit).

\section{Growing from maturity level 3 to 5: Key knowledge creation processes}

Similarly, considering the ICMM innovation capability maturity descriptions in

Figure1, the knowledge creation process(es) that acts as a key enabler for innovation capability maturity growth between maturity level 3 and maturity level 5 was identified through the following reasoning:

In order to grow from maturity level 3 to maturity level 5, the enterprise needs to improve its innovationrelated activities from a state where the ad hoc innovation-related activities have been formalised into best practices and procedures (the tacit knowledge that resides in the heads of workers have been made tangible) to a state where these formalised activities have been institutionalised.

What are the key knowledge actions (and therefore the key knowledge creation processes) that are needed to move from a state where activities are formalised to a state where activities are institutionalised? 


\begin{tabular}{l|l|}
$\begin{array}{l}\text { D. Esterhuizen } \\
\text { C.S.L. Schutte }\end{array}$ & Enhancing innovation capability maturity through \\
A.S.A du Toit & knowledge sharing
\end{tabular}

The key knowledge actions without which growth to the next maturity level is impossible are to encourage workers to 'learn' in order to institutionalise those best practices and procedures that have been formalised. Here the key knowledge creation process is internalisation; encouraging workers to embody the formalised explicit knowledge in their daily (innovation-related) activities.

Simultaneously, it is of equal importance to continuously 'rework' the current formalised innovation-related best practices and procedures in order to keep them aligned with the enterprises strategy and current operational requirements. Here the key knowledge creation process is combination; revising formalised explicit knowledge toward new explicit knowledge.

\section{Growing from maturity level 1 through to 5: The people component}

As identified in the previous two sections, growing from innovation capability maturity level 1 to maturity level 3 necessitates the knowledge creation process of externalisation, and growing from innovation capability maturity level 3 to maturity level 5 necessitates the processes of internalisation and combination.

A central theme emerges when considering the practical implications of these above-identified knowledge actions: the importance of the people component. Externalisation requires employees to convey their tacit knowledge to make it explicit, combination requires the reworking of explicit knowledge into new explicit knowledge (although mostly through the use of technology, never independent of human intervention), and internalisation requires that employees embody knowledge in their daily activities.

As the people component is a crucial element without which externalisation, combination and internalisation would be impossible, the underlying process supporting innovation capability maturity growth from maturity level 1 through to 5 is the need to facilitate 'sharing' through enabling tacit to tacit knowledge transfer through socialisation. The knowledge creation path (as depicted in Figure 2) acts as key enabler for maturity growth from maturity level 1 through to maturity level 5.

Figure 2: Key knowledge creation path enabling innovation capability maturity growth 


\begin{tabular}{l|l}
$\begin{array}{l}\text { D. Esterhuizen } \\
\text { C.S.L. Schutte }\end{array}$ & $\begin{array}{l}\text { Enhancing innovation capability maturity through } \\
\text { knowledge sharing }\end{array}$ \\
A.S.A du Toit &
\end{tabular}

\begin{tabular}{|c|c|c|}
\hline $\begin{array}{l}\text { Key knowledge process: } \\
\text { Externalisation } \\
\text { Define }\end{array}$ & $\begin{array}{l}\text { Key knowledge process: } \\
\text { Combination } \\
\text { Rework }\end{array}$ & $\begin{array}{l}\text { Key knowledge process: } \\
\text { Internalisation } \\
\text { Learn }\end{array}$ \\
\hline \multicolumn{3}{|l|}{ Explicit } \\
\hline \multicolumn{3}{|l|}{ Tacit } \\
\hline & Key knowledge process & \\
\hline & $\begin{array}{l}\text { Socialisation } \\
\text { Share }\end{array}$ & \\
\hline Maturity level 1 & Maturity level 3 & Maturity level 5 \\
\hline Ad hoc and limited & $\begin{array}{l}\text { Formalisation and } \\
\text { predictability }\end{array}$ & $\begin{array}{l}\text { Integration, synergy } \\
\text { and autonomy }\end{array}$ \\
\hline $\begin{array}{l}\text {... innovation-related } \\
\text { practices and procedures } \\
\text { are impromptu and limited } \\
\text { in their ability to fulfill the } \\
\text { requirements for consistent } \\
\text { innovation. }\end{array}$ & $\begin{array}{l}\text {... innovation-related best } \\
\text { practices and procedures } \\
\text { have been identified and } \\
\text { deployed, enabling the } \\
\text { consistent fulfilment of } \\
\text { the requirements } \\
\text { for innovation. }\end{array}$ & $\begin{array}{l}\text {... once formalisation has } \\
\text { been attained, } \\
\text { institutionalisation of } \\
\text { practices emerges, i.e. } \\
\text { where activities become } \\
\text { natural behaviour. }\end{array}$ \\
\hline
\end{tabular}

\section{EVALUATION OF FRAMEWORK}

A practical application of the framework in a real enterprise would prove or negate the hypothesis, and provides the obvious advantage of seeing measurable results as well as testing the adoption by users. Unfortunately, this is not a suitable evaluation method given the amount of time needed to practically test the framework could take anything up to five years or more, as innovation capability maturity growth takes time, especially when testing growth enablement through all five maturity phases. As the scope of this research study does not allow for practical implementation with real-life results, the hypothesis can be proven if it can be determined with fair confidence that the framework could enable innovation capability maturity growth, should the framework be used in a real organisation. Therefore, the hypothesis can be proved if the following is determined:

- That the idea of aligning knowledge creation processes with the requirements for innovation capability maturity growth from one maturity level to the next is valid. 


\section{Esterhuizen \\ C.S.L. Schutte \\ A.S.A du Toit}

\section{Enhancing innovation capability maturity through knowledge sharing}

- That the reasoning applied when identifying the specific knowledge creation process path as a key enabler of growth between innovation capability maturity levels is logical and sound.

- That the identified knowledge creation path accurately addresses the key requirements for growth from one maturity level to the next.

Subsequently, it was decided to conduct qualitative research by identifying five experts in innovation and knowledge management. Convenience sampling was used to identify the experts. Since the use of knowledge creation processes to enhance innovation capability maturity is a new concept in South Africa, it was necessary to handpick the experts with the assumption that they are information-rich individuals and that they would have an understanding of knowledge management and innovation capability maturity. The experts were considered to have a holistic view of knowledge management and are aware of the value of knowledge creation processes to enhance innovation. The five industry and subject theory experts from various fields each focused on the evaluation of the research methodology and framework. These interviewees were chosen to provide a broad perspective of the research. The framework was evaluated through responses to an evaluation questionnaire and/or through interview-based discussions. The downside of this method is that the interviewees could only respond from within their own experience and frame of reference as well as through consideration of what was presented to them.

The experts were asked to evaluate the accuracy of the identified knowledge creation path as a key enabler for growth between innovation capability maturity levels and whether or not they agree with reasoning applied by the authors when identifying this knowledge-growth path. Consequently they were also asked whether or not this knowledge-growth path accurately addresses the key maturity level description requirements for growth from one maturity level to the next.

Respondent $A$ is a keen researcher with extensive knowledge of and experience in the subject of innovation. He commented that the alignment of the knowledge creation processes with the requirements for innovation capability maturity growth "has been performed at a high level to create a generic and broadly applicable framework for applying knowledge processes to grow ICM - at the 'maturity level' level". He suggested that "future research could also be conducted to align knowledge process requirements and ICM requirements at a more detailed level." He also agreed with the reasoning applied when the knowledge creation path was identified as a key enabler of innovation capability maturity growth. From a framework applicability and usability perspective he found the structure of the framework clear and concise and commented that the framework is generic and does not stipulate specific activities, tools or methods, but "should a company go to the effort to select the appropriate tools using the framework and allocate them into the framework, it should be applicable and useful". He is also of the opinion that this path accurately addresses the key maturity level description requirements for growth from one maturity level to the next.

Respondent $B$ is a proficient researcher with extensive experience in the field of knowledge management, and although he has had limited formal exposure to the field of capability maturity models, he has a solid knowledge of the field of innovation. He agreed with the reasoning applied when the knowledge creation path was identified as a key enabler of innovation capability maturity growth. He confirmed that this identified knowledge creation path can be used to grow innovation capability maturity from one maturity level to the next, but remarked that "I would recommend that you make sure to specify that the growth path that you have identified isn't for the whole enterprise; just trying to manage it all". When asked whether he agrees with the structure of the framework, he replied "yes". He suggested that the word creation be substituted with discovery in the concept of knowledge creation processes. He also cautioned the authors to take care not to refer only to Nonaka, as he is part of the first wave of knowledge management: "If you use only Nonaka, you could create the impression that you think there is nothing else". After further discussion, respondent B was satisfied that the authors also views the knowledge creation processes as dynamic, and that this research is not based on Nonaka's linear approach. 


\section{Esterhuizen \\ C.S.L. Schutte \\ A.S.A du Toit}

\section{Enhancing innovation capability maturity through knowledge sharing}

Respondent $\mathrm{C}$ has considerable experience in information management consulting, with solid knowledge of the subject of capability maturity models and experience in the field of knowledge management. He agreed that it is important for an enterprise to grow and mature its innovation capability in order to innovate on a constant and sustainable basis, and that knowledge creation processes act as critical enablers for the innovation process. His comment on the question of whether or not he agrees with the idea of aligning knowledge creation processes with the requirements for innovation capability maturity growth from one maturity level to the next was: "Agree that it would assist enterprises with formalising the process of innovation". He thought that the identified knowledge creation processes do not accurately address the key maturity level description requirements for innovation capability growth. Asked whether he agrees with the specific knowledge creation process path identified as a key enabler of growth from one maturity level to the next, respondent C's reply was: "Yes, I completely agree; it makes sense". He gave a positive response from an applicability and usability perspective: "I think it's very applicable, and on the right level of detail. I find it practical".

Respondent $D$ has extensive experience in the field of capability maturity models, and although he has had limited formal exposure to the field of knowledge management, he has practical experience in the subject area in how it relates to the $\mathrm{CMMI} \AA^{\circ}$. He was in complete agreement with the specific knowledge creation path identified by the authors as a key enabler of innovation capability maturity growth between maturity levels. He was also satisfied that this identified path accurately addresses the key maturity level description requirement for growth from one maturity level to the next. From a framework applicability and usability perspective his response was "It is definitely usable and valuable within the context of the ICMM, and I think with a little adaptation, it will be valuable to the CMMI® community as well”.

Respondent $E$ is a keen researcher with solid knowledge of the subject of knowledge management and experience in the field of capability maturity models. She agreed with the reasoning applied in the identification of the knowledge creation growth path. She felt that even though innovation is enabled by more than just knowledge processes, "if you have limited your scope to knowledge management and innovation only, then I feel your proposal is the best 'link' as key enabler between the two". She also agreed with the specific knowledge creation path identified as a key enabler for innovation capability maturity growth, but was unsure what the authors meant with the socialisation process: "Does it imply that it runs across all CMM levels?" From a framework applicability and usability perspective, Ms Smuts commented that she "will definitely be able to apply the framework in practice". She commented that she found it easy to translate the guidelines into what it means for them as an organisation and for their innovation objectives, as she has prior knowledge of capability maturity models and knowledge management. She added that someone less experienced would be able to understand the framework, even though he or she may find it difficult to translate it to his or her work environment.

To conclude it can be stated that all five experts responded positively to, and were in agreement with, the following statements:

- That the idea of aligning knowledge creation processes with the requirements for innovation capability maturity growth from one maturity level to the next as the cornerstone of research toward a knowledge management framework to grow innovation capability maturity is valid.

- That the reasoning applied when identifying the specific knowledge creation process path as a key enabler of growth between innovation capability maturity levels is logical and sound.

- That this path accurately addresses the key requirements for growth from one maturity level to the next.

\section{CONCLUSION}




\section{Esterhuizen \\ C.S.L. Schutte \\ A.S.A du Toit}

\section{Enhancing innovation capability maturity through knowledge sharing}

The literature provides a strong basis for the argument that knowledge management and more specifically knowledge creation processes could be used to improve an enterprise's innovation capability maturity. A knowledge creation framework to grow innovation capability maturity was compiled. The fundamentals of the framework were derived through independent reasoning by the authors, by identifying a knowledge creation path that acts as a key enabler for maturity growth from maturity level 1 through to maturity level 5. Five industry and subject theory experts from various fields each evaluated the research by means of a written response to and/or an interview-based discussion facilitated by an evaluation questionnaire. These interviewees were chosen to provide a broad perspective of the research, while the evaluation questions were chosen to systematically cover all aspects of the research methodology. The results show an overwhelmingly positive response, with all five experts agreeing with the research methodology-related questions. It can therefore be stated with fair confidence that the following research hypothesis was proven: knowledge creation processes can be used to enable innovation capability maturity growth. The authors' emphasis was on researching generic knowledge management tool requirements and facilitating conditions, rather than specific tools, as this would ensure that the research remains applicable and relevant for a period of time surpassing the ever-changing technology-development landscape and would enable utilisation across a wider range of organisational domains.

The scope of this research study does not allow for practical implementation with real-life results, and consequently four research questions were designed to test whether it can be determined with fair confidence that the framework could enable innovation capability maturity growth, should the framework be used in a real enterprise. There is a gap in existing literature on the use of knowledge management toward innovation capability maturity growth. The unique research contribution of the framework therefore lies in providing a tangible link between the fields of knowledge management and innovation capability maturity. It should be emphasised that the framework is not a comprehensive solution to enable innovation capability maturity growth or an enterprise-wide knowledge management integration plan. Rather, the impact of this framework lies in providing guidelines for the use of knowledge creation processes as a vehicle for innovation capability maturity growth. In terms of future research, it is suggested that research could be conducted to align knowledge creation processes and innovation capability maturity requirements at a more detailed level. Furthermore, the conceptual nature of the research study leaves ample opportunity for further research into the practical application of the framework, as the ability of the framework to enable innovation capability maturity growth will only be determined via real-world implementation.

\section{REFERENCES}

Baker, K.A. 2002. Management benchmark study, Chapter 14: Innovation. [Internet. Available: http://www.au.af.mil/au/awc/awcgate/doe/benchmark; downloaded on 2011-04-21].

Bigoness, W.J. \& Perreault, W.D. 1981. A conceptual paradigm and approach for the study of innovators. Academy of Management Journal, 24(1):68-82.

BRINT.com. 2004. What is knowledge management: from recent peer-reviewed journals and books. [Internet: http://www.kmnetwork.com/kmdefs.htm; downloaded on 2011-02-26].

Calantone,R.J., Cavusgil, S.T. \& Zhao. Y. 2002. Learning orientation, firm innovation capability, and firm performance. Industrial Marketing Management, 31 (6):515-524.

Cavusgil, S.T., Calantone, R.J.\& Zhao,Y. 2003. Tacit knowledge transfer and firm innovation capability. Journal of Business \& Industrial Marketing, 18(1):6-21. 


\begin{tabular}{l|l|}
$\begin{array}{l}\text { D. Esterhuizen } \\
\text { C.S.L. Schutte }\end{array}$ & Enhancing innovation capability maturity through \\
A.S.A du Toit & knowledge sharing
\end{tabular}

Champlin, B. 2003. Toward a comprehensive data management maturity model (DM3), presented at Data Management International, St. Louis.

CMMI Product Team, 2002. Capability Maturity Model® Integration (CMMI®), Version 1.1. CarnegieMellon Software Engineering Institute, Pittsburgh.

Cooke-Davies, T.J. 2004. Measurement of organisational maturity: Questions for future research, in Innovations: Project management research. Newtown Square, PA: Project Management Institute.

Darroch,J. 2005.Knowledge management, innovation and firm performance, Journal of Knowledge Management, 9(3):101-115.

Davenport, T. H. 2005. Thinking for a Living. Boston: Harvard Business School Press.

Davenport, T.H. \& Prusak, L. 2000. Working knowledge: How organizations manage what they know. Boston, MA: Harvard Business School Press.

Degen-Hientz, H., Fäustle, M. \& Hörmann, K. 2005. CMMI®- An executive summary. [Internet; www.kuglermaag.com; downloaded on 2011-01-15].

Du Preez, N., Schutte, C., Essmann, H., Louw, L. \& Marais, S. 2009. Enterprise engineering textbook. Stellenbosch: Stellenbosch University.

Essmann, H.E. 2009. Toward innovation capability maturity. PhD thesis. Stellenbosch: Stellenbosch University. (Unpublished).

Fairchild, A.M. 2004. Information technology outsourcing (ITO) governance: An examination of the outsourcing management maturity model, in 37th Hawaii International Conference on System Sciences, Doi: 0-7695-2056-1/04.

Gourlay, S. 2006. Conceptualizing knowledge creation: A critique of Nonaka's theory.,Journal of Management Studies, 43(7):1415-1436,

Gupta, P. 2010. Business Innovation Maturity Model. [Internet: http://acelper.com; downloaded on 201104-03].

Hamel, G. 2000. Leading the revolution. Boston, MA: Harvard Business School Press. Innovation Practice. 2007. Innovation Aptitude ${ }^{T M}$ Audit. [Internet: www.theinnovationpractice.com; downloaded on 2011-03-25].

INPAQT. 2010. INPAQT Innovation Capability Maturity Model. [Internet: www.inpaqt.nl; downloaded on 2011-05-21].

Katz, B. 2007. The integration of project management processes with a methodology to manage a radical innovation project. MSc dissertation. Stellenbosch: Stellenbosch University. (Unpublished).

King, N., Kruger, N. \& Pretorius, J. 2007 Knowledge management in a multicultural environment: a South African perspective. Aslib Proceedings: New Information Perspectives, 59 (3):285-299.

LeVasseur, C. 2001. Describing the capability maturity model, Measure IT, Special Edition, Gartner. 


\begin{tabular}{l|l|}
$\begin{array}{l}\text { D. Esterhuizen } \\
\text { C.S.L. Schutte }\end{array}$ & $\begin{array}{l}\text { Enhancing innovation capability maturity through } \\
\text { knowledge sharing }\end{array}$ \\
\hline
\end{tabular}

Lin, H. 2007. Knowledge sharing and firm innovation capability: An empirical study. International Journal of Manpower, 28 (3/4):315-332.

Martensson, M. 2000. A critical review of knowledge management as a management tool. Journal of Knowledge Management, 4(3):204-216.

Mercer. 2008. Brainpower: rewarding knowledge workers. [Internet:

http://www.mercer.com/referencecontent.htm?idContent=1314145; downloaded on 2011-02-28]. .

Moore, G.A. 2005. Dealing with Darwin: How great companies innovate at every phase of their evolution. London: Penguin Books.

Murray, J. \& Rowan, E. 2000. Partnership for Innovation and Knowledge Transfer. [Internet: http://www.spottedcowpress.ab.ca/km/pdfs/09RowanMurray.pdf; downloaded on 2011-06-02].

Narayana, M.G.P.L. 2005. A framework approach to measure innovation maturity, Doi: 0-7803-9139-X/05.

Neely, A., Filippini, R., Forza, C., Vinelli, A. \& Hii, J. 2001. A framework for analysing business performance, firm innovation and related contextual factors: Perceptions of managers and policy makers in two European regions. Integrated Manufacturing Systems, 12 (2):114-124.

Nonaka, I.1994. A dynamic theory of organizational knowledge creation. Organization Science, 5(1):1437.

Nonaka, I. \& Toyama, R. 2003. The knowledge-creating theory revisited: Knowledge creation as a synthesizing process. Knowledge Management Research \& Practice, 1:2-10.

Nonaka, I., Toyama, R. \& Konno, N. 2000. SECI, Ba and leadership: A unified model of dynamic knowledge creation. Long Range Planning, 33:5-34.

Nonaka, I. \& Von Krogh, G. 2009. Tacit knowledge and knowledge conversion: Controversy and advancement in organizational knowledge creation theory. Organization Science, 20(3):635-652.

OVO. 2010. Innovation Maturity Model. [Internet: http://www.slideshare.net/jdpuva; downloaded on 201104-21].

PRTM. 2007. Innovation Maturity Model. [Internet:

http://www.innovationtools.com/PDF/Roadmap PRTM.pdf; downloaded on 2011-06-16].

Ruggles, R. \& Little, R. 1997. Knowledge management and innovation: An initial exploration. Working Paper. Boston: Harvard Business School Press.

Schumpeter, J.A. 1939. Business cycles: A theoretical, historical and statistical analysis of the capitalistic process. New York: McGraw-Hill.

Shrum, S. \& and Phillips, M. 2004. CMMI® overview for executives. Pittsburgh, PA: Carnegie-Mellon Software Engineering Institute.

Think For A Change. 2009. Innovation Maturity Model. [Internet: http://www.thinkforachange.com; downloaded on 2011-06-14]. 


\begin{tabular}{l|l} 
D. Esterhuizen & Enhancing innovation capability maturity through \\
C.S.L. Schutte & knowledge sharing \\
A.S.A du Toit &
\end{tabular}

Tidd, J. \& Bessant, J. 2009. Managing innovation: Integrating technological, market and organizational change, $4^{\text {th }}$ ed. Chichester: Wiley.

Tremblay, D.G. 2003. New Types of Careers in the Knowledge Economy? Networks and Boundaryless Jobs as a Career Strategy in the ICT and Multimedia sector. [Internet: http://hal.archives-

ouvertes.fr/docs/00/19/01/24/PDF/Tremblay 2003.pdf; downloaded on 2011-03-24]. . 